\title{
INTERVENTION IN MEXICO. SAMUEL GUY INMAN Y LA CUESTIÓN MEXICANA
}

\author{
Alexandra Pita \\ Universidad de Colima
}

INTRODUCCIÓN

Pobre México, tan lejos de Dios, tan cerca de Estados Unidos

\begin{abstract}
F sta famosa frase (adjudicada a Porfirio Díaz) tomó mayor Esentido en ciertos momentos en los que la relación entre ambos países entró en crisis. Uno de ellos fue tras el inicio de la revolución mexicana, cuando la palabra intervención se convirtió en un leitmotiv. Aunque las tropas estadounidenses se retiraron de Veracruz en noviembre de 1914, las tensiones continuaron incrementándose en 1917, después de la promulgación de la Constitución. Los siguientes dos años se generó una escalada de hechos que crisparon nuevamente la relación. Una manera de observar este complejo entramado es por medio de las publicaciones que buscaron desde el poder de la palabra lanzar una contraofensiva política para convencer a la
\end{abstract}

Fecha de recepción: 10 de octubre de 2018

Fecha de aceptación: 25 de febrero de 2020 
opinión pública del error que sería intervenir. Esto nos permite comprender la delicada influencia de los medios de prensa en Estados Unidos y el uso que de ellos hicieron diferentes grupos de presión en un conflicto que fue conocido como "la cuestión mexicana". ${ }^{1}$

En este sentido, el presente artículo analiza un libro, Intervention in México (1919), y su autor, Samuel Guy Inman, misionero protestante que con sus publicaciones intentó formar a la opinión pública mediante una campaña propagandística. Inman fue un líder destacado de este movimiento "progresista norteamericano que luchaba contra la corrupción del capital”, convirtiéndose en un “orador de la revolución”. Por ello Jean Pierre Bastian lo calificó de intelectual popular. ${ }^{2}$ Pese a la importancia de este personaje como aliado primero del maderismo y luego del carrancismo, se ha investigado poco sobre él y de este libro en particular. El historiador estadounidense Kenneth F. Woods publicó un artículo sobre el libro en la década de 1960. En él muestra cómo la oposición entre intervencionistas y no intervencionistas fue una lucha importante en Estados Unidos, y que dentro de los que se oponían a una invasión jugó un papel importante un sector del movimiento protestante. Liderados por Inman éstos realizaron una campaña publicitaria pro

\footnotetext{
1 Meyer aporta una idea clara sobre lo que son los grupos de presión: cumplen un papel fundamental en la política, ya sea que pertenezcan al aparato gubernamental o no, al reunir un conjunto de individuos que conscientemente manifiestan el deseo de influir en una discusión política, por lo que combinan sus esfuerzos. MeYer, Los grupos de presión, pp. 21-22.

2 El autor define a los protestantes que participaron en esta red como intelectuales populares porque difundían sus demandas a un nivel popular, de masas. Aclara que algunos pertenecían a este sector al ser o haber sido obreros, pero también eran líderes de sociedades mutualistas y militaban en la masonería. Pese a esto, no representaban al sector más radical de la clase obrera porque su función era "preparar el terreno político" al "educar al pueblo en sus deberes como ciudadanos”. BASTIAN, “Los propagandistas”, pp. 321, nota 32, 326 y 331 .
} 
intervencionista al lanzar otra más conciliadora. Aunque este artículo representa una gran aproximación al tema y aporta una serie de datos de gran relevancia, se dedica a explicar el contexto previo y posterior, más que a analizar la obra. ${ }^{3}$ Posteriormente el libro sólo sirvió como mención al considerarlo parte de las acciones políticas emprendidas por liberales estadounidenses. Esta visión de conjunto descontextualiza la obra de su autor, motivo por el cual en las siguientes páginas se prestará atención a explicar algunas de las acciones previas tomadas por Inman como líder misionero. Esto implica que temporalmente no nos circunscribimos al año de 1919 sino que nos remitimos a 1910 para dar una somera explicación del autor y su relación con México y América Latina. De igual modo, el estudio se extiende hasta 1920 para explicar los primeros impactos que tuvo la publicación de esta obra. Cabe aclarar que las fuentes primarias a las que tuve acceso no me permitieron hacer una historia de la producción y recepción del libro, pero creo que permite retomar un objeto de estudio olvidado por la historiografía mexicana para entender el valor no literario sino político de una obra dentro de una campaña propagandística. ${ }^{4}$

3 Woods, "Samuel Guy Inman and Intervention in Mexico", pp. 351-370. En un trabajo anterior dedicado al estudio en general de Inman, Woods plantea el contexto previo y con el uso de prensa y el libro hace un esquema del libro y su impacto positivo en la prensa y negativo en el Comité del Senado conocido como Fall. Este material se utilizó para el artículo posterior, pero es más completo el artículo por lo que nos remitimos a éste y poco a la tesis en las citas. Woods, "Samuel Guy Inman".

${ }^{4}$ Lamentablemente no se ha podido acceder a la colección que guarda la Biblioteca del Congreso de los papeles de Inman. Sin embargo, en Estados Unidos se pudo consultar en la Universidad de Columbia el fondo de Inman. En México, se encontró información relacionada en el Archivo Histórico de la Secretaría de Relaciones Exteriores de México. También se buscó en el Archivo CEHM, encontrando poca información (lo cual es extraño dada la cercanía entre Inman y Carranza). A esto se añade un documento del CEDINCI en Buenos Aires y la consulta del libro, así como de la comparecencia de Inman 
INMAN. MISIONES, REVOLUCIÓN Y PANAMERICANISMO

La historia del autor está íntimamente relacionada con la de las misiones del protestantismo en América Latina y en especial en México. ${ }^{5}$ Samuel Guy Inman (1877-1965) estuvo involucrado en la Iglesia protestante desde muy joven, conjugando sus estudios con actividades extracurriculares en diversas organizaciones de la Iglesia de los Discípulos de Cristo. Tras una serie de cambios, aceptó un trabajo en la Iglesia de esta congregación en la ciudad de Nueva York, donde al mismo tiempo estudió en la Universidad de Columbia. Después de graduarse (en 1902) se trasladó con su esposa a México para trabajar como misionero en Monterrey, Saltillo, y poco después en Piedras Negras (en ese entonces, Ciudad Porfirio Díaz). ${ }^{6}$

Ahí fundó un centro llamado El Instituto del Pueblo donde, amén de enseñar inglés y otras habilidades, se reunía por las

ante la Comisión Fall, material que pese a estar publicado es parte de las fuentes primarias utilizadas.

${ }^{5}$ La presencia protestante en América Latina puede rastrearse desde la época de la colonia en el siglo xvi por medio de agentes (mercaderes, viajeros y corsarios) y literatura. Pero a ese "protestantismo nativo" se sumaron tras la independencia los misioneros protestantes escoceses, ingleses y estadounidenses de distintas denominaciones (bautistas, presbiterianos, metodistas, congregacionistas, anglicanos, etc.), quienes se pusieron en contacto con los grupos preexistentes. En México, fue José Luis María Mora, un clérigo liberal, quien dio mayor soporte a la difusión de las ideas protestantes al estar convencido de la necesidad de expandir la lectura de la biblia entre las masas con el fin de elevar su moral. Mora no se convirtió, pero compartió con muchos otros liberales y masones el interés por promover las actividades protestantes para pelear por una mayor libertad religiosa. A fines del siglo xIX se institucionaliza el protestantismo, pero a nivel ideológico su carácter mantiene el espíritu disidente, situación que lo acerca a otros disidentes que se enfrentaban a la Iglesia católica y a la idea de un gobierno pro católico (liberales, masones y librepensadores). Mondragón, Like Leaven in the Dough, pp. 46-50.

${ }^{6}$ Sobre la infancia y juventud de Inman en Texas, así como sobre su pronta participación en actividades de la Iglesia remitimos a Castleman, On This Foundation. 
noches un grupo de hombres de clases acomodadas a discutir temas "morales y sociales de actualidad". Dado el éxito obtenido, reunió una suma considerable de donaciones para construir un edificio donde se estableció una biblioteca pública y se daban clases a los menos favorecidos. En 1913, cuando Carranza estableció su cuartel en esta ciudad, tomó el Instituto como centro de operaciones y se estableció una amistad entre ambas familias. Asombrado por el proyecto educativo, Carranza envió a varios maestros y jóvenes a estudiar a Estados Unidos en escuelas protestantes. De hecho, cuando su ejército tomó la ciudad, el Instituto se convirtió en su cuartel general, pero tras el ingreso de las tropas de Victoriano Huerta y el complejo desenlace que llevó a la intervención de 1914, Inman tuvo que abandonar el país. ${ }^{7}$

Durante su estancia en México, Inman publicó varios artículos en la prensa protestante, principalmente en The Christian Evangelist y The Christian Century. Además, gracias al apoyo de la organización religiosa The Christian Woman's Board of Missions (сшвм), publicó tres escritos: The Crucial Hour in Latin America (1908), The Mexican Question (1911) y "No comprendo" A message from Mexico (1913). En ellos expresaba su fe en la revolución y en que se pudiera crear un verdadero panamericanismo. ${ }^{8}$ En estos y otros textos de su autoría era

7 Williams, Radical Journalists, pp. 47-50.

${ }^{8}$ El primero era un análisis sobre la situación en América Latina y sus potenciales, los cuales a su juicio eran enormes puesto que desde que se abrió el canal de Panamá se inició un cambio visible tanto en lo económico como en lo intelectual. Sólo la Iglesia cristiana ha declinado ser parte de este cambio, afirma, pues sigue siendo pequeña su presencia en todos los países, por lo que es importante reforzar su trabajo en la región. En el segundo escrito plantea que la cuestión mexicana es el problema más complejo que tiene Estados Unidos, pues no puede resolverlo por la guerra ni por la diplomacia. Las personas han sido dominadas por los curas y los señores de la tierra desde la conquista hasta el presente y gradualmente la clase media ha ido despertando. Los misioneros deben apoyar este proceso porque su religión puede mostrar una oportunidad de interés en los líderes mexicanos, rompiendo los prejuicios sobre el protestantismo y mostrándose como un factor de cambio del país. En 
evidente que se justificaba la revolución ante el autoritarismo de Díaz y su alianza con una Iglesia católica corrupta que mantuvo al pueblo mexicano en la miseria. En cambio, el maderismo era visto como un aliado al buscar el progreso y atacar los excesos de la Iglesia de Roma. Por ello no es extraño que una vez que se inició el conflicto, llamó a los otros misioneros a apoyar al movimiento revolucionario no para derramar sangre, sino para esgrimir los evangelios. ${ }^{9}$

Inman informó al consejo en Estados Unidos sobre la insurrección del 19 de noviembre, preguntándose qué camino seguiría el movimiento, aunque sin dudar que el régimen de Díaz caería inevitablemente y que era un privilegio ser parte de ese "nuevo orden de cosas". Casi todos los misioneros expresaron su simpatía por la rebelión de Madero y tras asumir la presidencia pensaron que sería una gran oportunidad para consolidar su influencia. Tras su asesinato, algunos misioneros compararon el régimen de Huerta con el de Díaz, mostrando su desacuerdo e involucrándose en la revuelta de Carranza y la posterior lucha del constitucionalismo. Sin embargo, ante el deterioro de la situación entre Estados Unidos y el presidente Huerta, muchos protestantes debieron salir del país. ${ }^{10}$

Al regresar a Estados Unidos, Inman se involucró en un movimiento religioso que desconocía la postura adoptada años antes por el Congreso de Edimburgo (1910) por excluir a América

el tercero reafirma que el cambio estaba justificado porque se pasó del despotismo a la democracia y que era imposible que esto se realizara sin disturbios (como lo muestra la historia en repetidas ocasiones). Los discípulos de Cristo deben ayudarles a comprender el valor del cambio, pero para eso deben crecer las misiones puesto que actualmente no son suficientes. Por ello termina preguntando al lector si podría dar generosamente su trabajo para esta causa. Véanse Inman, The Crucial Hour in Latin America; The Mexican Question; y "No comprendo": A message from Mexico.

9 Bastian, "Los propagandistas", p. 326.

10 Baldwin, Protestants and the Mexican Revolution, pp. 70-71, 123, 127, $133,144$. 
Latina de sus prioridades. Liderada por Robert E. Speer, un distinguido ministro presbiteriano, se fundó la Junta de Misiones Estadounidense, la cual publicó una serie de escritos, entre ellos el panfleto de Speer "The Case for Missions in Latin America” (1912), y celebró una conferencia en Nueva York (marzo 1913).$^{11}$ De ahí surgió la idea de crear el Comité de Cooperación en América Latina. Para legitimarlo, Inman se dedicó a escribir a otros misioneros para expresar sus propósitos y programa, solicitando su participación en una próxima conferencia a realizarse en Panamá. Entre enero y julio de 1914 Inman viajó por América Latina para reunirse con todos los grupos de misiones a fin de escuchar sus opiniones sobre la conferencia propuesta. Durante el tiempo que duró este viaje, la situación entre México y Estados Unidos entró en crisis derivando en la invasión del puerto de Veracruz en abril de 1914 y su ocupación durante siete meses. Esto significó un fuerte revés para las misiones, las cuales se reunieron en la ciudad de Cincinnati en julio de 1914 (en la Conferencia de Misiones) y en la Junta Misional en México) para analizar la situación. ${ }^{12}$

En su diario de viaje, Inman anotó la situación de las misiones y de la población, así como las condiciones económicas y políticas de cada país visitado. No le resulta ajena la ola de críticas que existía por la injerencia del Tío Sam en la región, aunque

11 Fediakova, "Protestantismo misionero norteamericano”, p. 13. CARdoza Orlandi, "From Christian Continent to mission field", pp. 13, 23, 86 y 97.

12 "El tour de investigación” de Inman, como lo anunciaron en la prensa, inició en febrero de 1914 cuando salió de Nueva York rumbo a Jamaica y Puerto Rico, luego cruzó el istmo de Panamá parando en Ecuador, Perú y Chile donde estudió el estado de las misiones de los Discípulos de Cristo y de otras iglesias. En Santiago tomó el tren transcontinental a Buenos Aires, Argentina, donde pasó un tiempo inspeccionando las condiciones y el trabajo realizado por la misión. Continuó hacia Uruguay y Brasil para regresar a mediados del verano de 1914 y realizar un reporte presentado al comité ejecutivo del Committee of the Woman's Board. Ida H. Harrison, “The Commission on Latin America, of the Disciples of Christ”, en The Christian Century (7 ene. 1915), p. 15. 
sutilmente señalaba cómo muchos seguían admirando a Estados Unidos por ser un ejemplo de progreso. ${ }^{13}$ Para él y otros protestantes del comité era necesario corregir los defectos y las debilidades de los latinoamericanos, pero a diferencia de las posturas intervencionistas, creían que esta corrección debía hacerse mediante el fortalecimiento de sus aspectos morales y sociales. Más que una intervención militar era necesario alejarlos de la maldad que fue inoculada por el extenso y corrupto periodo del presidente Díaz, con la anuencia de la Iglesia católica. ${ }^{14}$

La primera reunión del Comité de Cooperación en América Latina se realizó en Nueva York el 22 de septiembre de 1914, y se eligió a Robert Speer como director y a Inman como secretario ejecutivo. Para el 5 de noviembre la oficina quedó constituida en el edificio presbiteriano en el número 156 de la Quinta Avenida en Nueva York. ${ }^{15}$ De inmediato se puso en marcha la organización del congreso en Panamá, el cual se realizó en febrero de 1916 con la asistencia de numerosas organizaciones misioneras de los Discípulos de Cristo. ${ }^{16}$

Para reforzar sus ideas en torno a la relación que debía existir entre ambas Américas, Inman publicó su primer libro, Christian Cooperation (1917). En él precisó que las misiones podrían

13 Por ejemplo, de su primera parada en Puerto Rico, donde se quedó dos semanas, anotó que ahí “uno puede encontrar el laboratorio del Tío Sam” al observar cómo el gobierno está utilizando sus recursos para enseñar al pueblo inglés. En cambio, Jamaica tiene un problema crónico y nadie espera que mejore en el futuro. En ese lugar, pese a tener misioneros nativos que tienen una "educación superior a la de cualquier otra iglesia ahí", la labor entre los negros “ignorantes y supersticiosos” era extremadamente difícil. Al llegar a Chile, lo sorprendió el contraste con Perú y Ecuador, y al visitar Buenos Aires se quedó maravillado, igualándolo a Nueva York para Sudamérica, tan "distinto de los elementos latinos”. Samuel Guy Inman, "Mission Scouting in South America”, en The Christian Century (4 feb. 1915), pp. 6 y 7.

14 Lou, "Fall Committee", p. 58.

15 Christian Work in Latin America, Nueva York, The Missionary Education Movement, 1917, pp. 9-12.

16 Inman, The Panama Congress and the Disciples of Christ. 
limitarse por las tensiones creciente entre Estados Unidos y los países latinoamericanos. Durante su viaje por América del Sur, advirtió el aumento de estas críticas, aunque consideró que esta actitud había cambiado ligeramente gracias al idealismo del presidente Woodrow Wilson y al ingreso de este país en la guerra. Por eso, impulsó la idea del panamericanismo como una solidaridad continental, lo cual implicaba reinterpretar la Doctrina Monroe para entenderla como una herramienta de justicia internacional y no como una imposición regional. ${ }^{17}$

De manera paralela, Inman se involucró en otras organizaciones que excedían los límites de lo religioso. En 1910 participó en la IV Conferencia Panamericana realizada en Buenos Aires, no como delegado de Estados Unidos, pero sí como un observador acucioso. Su conocimiento de América Latina le permitió detectar las tensiones y preocupación entre los representantes de estos países. Registró una serie de encuentros privados donde bajo la excusa de tratar sobre la conmemoración de los centenarios, se plantearon otros temas políticos como el arbitraje, la Doctrina Drago y Calvo y, claro está, las implicancias de la Doctrina Monroe y el papel de Estados Unidos como el "gran hermano que vigila y protege". ${ }^{18}$

\section{LAS TENSIONES BILATERALES Y LAS CAMPAÑAS \\ DE LOS GRUPOS DE PRESIÓN}

Tras la toma del puerto de Veracruz por parte de Estados Unidos en 1914 y la renuncia del presidente Huerta, se produjo una nueva lucha de poder entre los revolucionarios (Zapata, Villa y Carranza). La situación interna era intensa y complicada, por lo que para los líderes era importante conseguir el reconocimiento de Estados Unidos, el cual llegó a fines de 1915 a

17 Pita, “Panamericanismo y Nación”, p. 144.

18 Pita, “Panamericanismo y nación”, pp. 139-142. 
Carranza como presidente de facto. Sin embargo, entre 1915 y 1917 la relación entre ambos países se tensó más por una escalada de acciones. ${ }^{19}$

Las tensiones continuaron aumentando al ser promulgada la nueva constitución mexicana (sobre todo por el art. 27). ${ }^{20}$ Pero el ingreso de Estados Unidos a la primera guerra mundial en 1917 hizo que el problema mexicano fuera relegado a un segundo plano. Tras el discurso (de los 14 puntos) que dio el presidente Wilson, se fundó la League of Free Nations Association (Liga de la Asociación de Naciones Libres, mejor conocida como Liga de Naciones Libres) el 18 de abril de 1918 con sede en Nueva York. ${ }^{21} \mathrm{~A}$ inicios del siguiente año, la dirección de esta Liga

${ }^{19}$ En marzo de 1916 Francisco Villa atacó Columbus y de manera casi inmediata el país vecino envió a su ejército al mando del general Pershing con el fin de capturarlo, expedición punitiva que prolongó la presencia de este ejército en tierras mexicanas hasta febrero de 1917. Mientras tanto se reunieron en la Constituyente en México para discutir la nueva Constitución entre octubre y noviembre, la cual se promulgó el 5 de febrero de 1917 (mismo día que terminó la expedición punitiva). Además, tras el hundimiento del barco Lusitania en 1915 y el conocimiento en Estados Unidos del telegrama Zimmermann (enero de 1917), la opinión pública se tornó favorable a la incorporación en la primera guerra mundial, la cual se dio en abril de 1917 (pese a las resistencias del presidente Wilson).

20 En febrero de 1918 México decretó que, independientemente de la fecha de adquisición, los depósitos petroleros eran de la nación. La discusión en torno a la retroactividad de la medida se convirtió en la pieza clave de la discusión, pues para Estados Unidos era una confiscación de bienes. Carranza tuvo que dejar en suspenso la aplicación de las medidas, pero no las anuló. Ante el incremento de la campaña intervencionista en el país vecino, Carranza buscó apoyo en América Latina por medio de una política de acercamiento conocida como "la doctrina Carranza" con la cual se buscaba rechazar la Doctrina Monroe y crear una alianza (defensiva) con los otros países de Latinoamérica a fin de tomar control de los recursos nacionales y frenar el predominio de los extranjeros. VÁzquez y MeYer, México frente a Estados Unidos, pp. 146-147.

${ }^{21}$ La falta de claridad sobre esta organización comienza con el nombre. Hay autores que la traducen como Asociación por la Liga de las Naciones Libres, y otros como Liga de la Asociación de las Naciones Libres. Decidimos usar esta última porque en ocasiones la abrevian como Liga de las Naciones 
recayó en James McDonald. ${ }^{22}$ El propósito de la Liga era desarrollar una nueva forma de organización mundial que "removiera las causas de la guerra y construyera una relación más cercana y amigable entre las naciones", es decir, apoyaba los planes del

Libres, por lo que consideramos que el calificativo Asociación era para distinguirla del proyecto de la Liga de Naciones y de otras ligas similares en otros países. La primera de este tipo apareció en Inglaterra, teniendo al escritor $\mathrm{H}$. G. Wells entre sus participantes (algunos autores afirman que fue en 1916 y otros, en 1918). En Estados Unidos todos coinciden en que se creó en 1918 con sede en Nueva York y que pocos años después (unos dicen 1921; otros, 1922; y otros sostienen que fue en 1923) se convirtió en la Foreign Policy Association. El iniciador fue Paul Kellogg, quien había regresado recientemente de Europa con la convicción de que era necesario apoyar los principios democráticos expresados por Wilson para establecer la paz y un nuevo orden mundial. Kellogg era editor de The Survey y el presidente de la Conferencia Nacional de Trabajo Social; en abril de 1918 reunió a 18 amigos, muchos de ellos liberales que trabajaban en la prensa y que se habían convertido en exponentes de la democracia en asuntos extranjeros durante la primera guerra mundial. La primera constitución de este cuerpo fue adoptada en diciembre de 1918, cuando su declaración de propósitos decía que debía estudiar cuidadosamente todos los lados de todas las cuestiones internacionales que afectaran a Estados Unidos y comunicar dichos resultados al mayor número de americanos posibles. 22 James G. McDonald nació en 1886 en Ohio en una familia católica (de padre canadiense y madre inmigrante de Alemania). Tras casarse con Ruth Stafford, de familia metodista, McDonald se fue a España becado para investigar (durante la primera guerra mundial), debido a que era estudiante de doctorado de Harvard (el cual no terminó). Durante dicha estancia desistió de seguir con esa investigación y escribió un panfleto que fue considerado de propaganda alemana, idea que cambió poco después a medida que avanzaba la guerra. En 1917 defendía el ingreso de Estados Unidos a la guerra mundial. A su regreso a Estados Unidos renunció a su puesto en la Universidad de Indiana y se trasladó a Nueva York, donde trabajó primero en la National Civil Reform League (Liga nacional civil del servicio de reforma); en enero de 1919 toma el puesto como director de la Liga de la Asociación de Naciones Libres, la cual luchó -sin éxito- para que Estados Unidos se uniera a la Sociedad de las Naciones, defendiendo los principios del presidente Wilson. Poco después, cambió de nombre por el de Asociación de Política Exterior, donde McDonald se mantuvo como presidente hasta 1933. MCDonald, Advocate for the Doomed, pp. 4-5. 
presidente Wilson para que una vez finalizada la guerra, este país participara en un nuevo organismo internacional. En julio de 1919 se creó dentro de la Liga el Comité de Relaciones Mexicanas, el cual debía enviar material a la prensa de Estados Unidos de manera regular contando los "hechos verídicos" de México, y además debían formular una propuesta para una política “económica y socialmente justificable”. ${ }^{23}$ Además, fomentó la publicación de una serie de libros antiimperialistas (considerados por la crítica como de propaganda bolchevique), con la intención de denunciar los intentos de conspiración contra México. Entre éstos el primero fue el de Samuel Guy Inman, Intervention in Mexico (agosto 1919), seguido pocos meses después en ese año por el de Arthur Thomson, The Conspiracy Against Mexico, y el de Leander J. De Bekker, The Plot Against Mexico. Y al año siguiente el libro de J.K. Turner, Hands off Mexico (1920). ${ }^{24}$

Este cambio de orientación de los problemas mundiales a la cuestión mexicana se relacionaba con los últimos sucesos. A inicios de 1919, mientras se iniciaba la Conferencia de Paz en París (que finalizaría en junio con el origen de la Sociedad de las Naciones), se creó en Estados Unidos un grupo de presión llamado Asociación Nacional para la Protección de los Derechos Americanos en México, la cual -encabezada por el empresario petrolero Edward L. Doheny- aprovechó el foro internacional para difundir sus demandas. ${ }^{25}$ A éste se sumó en el mismo año el Comité de Banqueros, el cual expresó su preocupación por la

23 Woods, "Samuel Guy Inman”, pp. 354-357. O'BRIEN, “Oil, diplomacy and intervention", pp. 70-71.

24 Spenser, El triángulo imposible, pp. 32-33.

25 En 1919, Doheny llevó a la Conferencia de Paz en París una delegación para demandar los derechos de los propietarios en México a establecer un acuerdo internacional que asegurara su propiedad (y se aliaran con ellos contra Carranza), medida que no fue aprobada. Tras este fracaso optó por otra estrategia: cooperar con el Comité de Investigación del Senado de Estados Unidos para desacreditar al gobierno de Carranza. En 1920, fue sustituida por la Asociación Americana de México. MeYer, Los grupos de presión, pp. 74-75. 
falta de garantía del gobierno de Carranza de pagar las deudas. Los principales medios de prensa se dividieron a favor o en contra de los grupos intervencionistas. Algunos fueron hostiles a México impulsando una intervención armada y otros, más liberales, insistían en mantener las relaciones diplomáticas como medio para solucionar las diferencias entre ambos países. ${ }^{26}$

La posición del gobierno estaba dividida. Mientras el presidente Wilson defendió que México debía arreglar sus problemas, el Departamento de Estado advirtió que, si no modificaban el rumbo, se procedería a una intervención. Los autores de estos envíos eran el subsecretario, el secretario Lansing, el embajador en México, Henry Fletcher, y el secretario del Interior, Frank Lane. Otro grupo de intervencionistas fue el que se reunió en torno al senador de Nuevo México Albert Fall. Entre los argumentos esgrimidos por los intervencionistas se utilizó el de la confiscación de las propiedades estadounidenses en México, el cual era utilizado como sinónimo de bolchevismo, fantasma que temían se apoderara de México y se expandiera al resto de los países de América Latina. ${ }^{27}$ Estos grupos aprovecharon dos sucesos entre julio y agosto de 1919 para alertar a la opinión pública y ratificar la necesaria e inminente intervención: el incidente del "monitor" Cheyenne y la captura de dos pilotos estadounidenses que aterrizaron en Chihuahua. ${ }^{28}$

Por su parte, Inman escribió un reporte de la situación para el Consejo de las Misiones Extranjeras de la Iglesia Presbiteriana (julio 1919). Ahí acusó a los hombres del petróleo de forzar al gobierno de Estados Unidos a iniciar una guerra para controlar este recurso de millonarias ganancias. Advertía del uso que habían hecho de la propaganda y de que, si esta medida se llevaba a cabo, sería el fin de todas las misiones americanas en ese país, por

${ }^{26}$ Matute, "El fantasma de la intervención”, pp. 80-83.

27 SPenser, El triángulo imposible, pp. 29-31.

${ }^{28}$ Matute, "El fantasma de la intervención”, pp. 86-87. 
lo que finalizó alentando a los misioneros a que escribieran cartas a los hombres del Congreso para impedir una intervención. ${ }^{29}$

\section{LAS CONDICIONES Y LA EVOLUCIÓN DE MÉXICO. UN LIBRO PRAGMÁTICO}

En medio de esta batalla se publicó en agosto de 1919 el libro Intervention in Mexico. Destinado a un público amplio, tenía una portada simple (sin más imágenes que el logo de la editorial Association Press de Nueva York), un lenguaje sencillo y un precio accesible (1.50 dólares). Las 266 páginas se dividían entre un breve prefacio, seis capítulos y un anexo (dedicado a un plan para establecer un centro educativo financiado por los amigos de México en Estados Unidos).

El prefacio fue escrito por William R. Shepherd, profesor estadounidense de la Universidad de Columbia, ${ }^{30}$ quien tenía contacto con Inman y otros grupos pro mexicanos. ${ }^{31}$

29 “Missionary’s report accuses oil men”, New York Times (7 ago. 1919).

30 Shepherd (1871-1934) fue un historiador y cartógrafo estadounidense especializado en historia de América Latina. Estudió en la Universidad de Columbia donde tras su regreso de Berlín se convirtió en profesor. Participó en la Asociación Histórica Americana y fue autor de un conocido atlas histórico de América (primera edición en 1911).

31 Por un intercambio epistolar entre Shepherd y el mexicano Federico González Garza, sabemos que el profesor no era miembro del Consejo de Relaciones Exteriores de Estados Unidos ni ocupaba ningún otro cargo como funcionario. Al parecer, el desacuerdo entre ambos se debía a que este consejo había convocado a un banquete en Nueva York y pese a que Shepherd había aceptado presidirlo no se aceptó la lista de oradores que sugirió para dar un mensaje de "amistad y buena voluntad" (entre los que estaba González Garza, Prado, Garza Aldape, Castellot e Inman). En cambio, el secretario del Consejo, Dunbar, eligió otros oradores que divagaron y vociferaron contra Carranza, los bolcheviques, etc. Aprovecha para aclarar, en su discurso de esa noche, que no es hostil a los latinoamericanos y mucho menos aliado de los intervencionistas. CEHM, CMXV. 49. 4827. 1 y 4838.1 carta de Garza a Shepherd, 14/03/1919 y de Shepherd a Garza, 18/3/1919. 
En él realizó un paralelismo entre la guerra civil de Estados Unidos y la revolución mexicana: ambas provocaron que la nación estuviera despedazada en una guerra sin fin, con problemas políticos serios que duraron varios años. La gran diferencia es que, en su caso, las convulsiones por la guerra civil no generaron pérdidas significativas para los extranjeros mientras que, para desgracia de México, sí existen ciudadanos estadounidenses afectados. Eso lo lleva a preguntarse sobre la política que lleva el vecino del norte sobre México. Es evidente que México es un país independiente y soberano, pero los disturbios y el desorden hacen que el gobierno estadounidense dude en considerarlo ( $\mathrm{y}$ tratarlo) como una verdadera nación extranjera o como parte de esa "política doméstica" que su país tiene con los otros países del Caribe. La cuestión es si esto justifica la interferencia. La respuesta ha sido usualmente afirmativa y se ha ampliado al modificar su léxico (y su práctica) de interferir a intervenir. Sin embargo, como nación independiente y soberana, México tiene "absoluto derecho de adoptar la constitución que más le plazca”. Incluso si se equivocan -y pagan el precio por ello-, no debe perder ese derecho, porque, aunque nunca haya sido una nación completamente independiente, una intervención es técnicamente una conquista, la cual no tiene ninguna justificación, sino que sería sólo un castigo.

En ese punto, atacó un tema sensible al recordar que México había sido acusado de ser "pro germano" durante la guerra. Pero si el gobierno de ese país no era reconocido y sufría todo tipo de interferencias, debería entenderse su actitud como un acto de defensa. Aludiendo al nacionalismo, consideraba que de haber una intervención esto no sería un "bien para los mexicanos". Advierte que no deben esperar que la intervención que ha realizado su país en las pequeñas repúblicas del Caribe sea igual que la de México, con una población numerosa y heterogénea donde una guerra así podría convertirse en un conflicto "de color y raza”. ¿Es que no existe una salida mejor? En respuesta 
acude a Inman, “quien conoce a los mexicanos y aún sigue siendo un americano". 32

Tras cederle la palabra, Inman abre con una serie de términos sueltos (como si se tratara de titulares de prensa): México está en primera plana de los periódicos; potencias organizan comités de banqueros para estudiar la "cuestión mexicana”, mientras petroleros crean una organización para proteger sus derechos; congresistas demandan reportes y el Departamento de Estado vigila de cerca; el Consejo de Relaciones Exteriores crea un comité para que le den ideas al respecto; capitalistas aportan un fondo generoso para asistir a un grupo de profesores universitarios para investigar asuntos sociales y educativos mexicanos. Con ello quiere demostrar que todos están interesados en México, pero ninguno tiene la verdad porque los periódicos generan confusión mezclando información y dando datos erróneos. En cambio, él pretende dar una visión fresca y auténtica del país en el que ha vivido muchos años. Es consciente de que es fácil que la opinión pública se equivoque porque existe un desconocimiento del México real, no el que aparentaba la superficie de progreso material durante el régimen de Díaz, sino el del México que ha sido "abusado" por el poder absoluto de una sola persona. Otro malentendido es sobre la Constitución de 1917. Si se conociera mejor la de 1857 se darían cuenta de que es muy similar y que los artículos nuevos son necesarios para unir a un país con grandes diferencias. ${ }^{33}$

\footnotetext{
32 Inman, Intervention in Mexico, pp. vii-xi.

33 Inman utiliza el término indios para referirse al pueblo mexicano; tiene conciencia de que éstos representan la mayoría de la población, pero se niega a reconocer que todo el país es indio pues los jóvenes progresistas no lo son, ellos son identificados generalmente como liberales, modernos. Alcanza a vislumbrar que existe una diferencia entre el norte del país, progresista (y menos indio) y el sur, conservador en los “estados indios”. Su condición actual no dista mucho de la que tuvieron durante la conquista española, cuando se les consideraba casi esclavos.
} 
Es esta ignorancia lo que les impide ver la complejidad del problema. Refiriéndose al presidente Woodrow Wilson como al hombre más criticado en su país desde Lincoln, les recuerda lo complicado que ha sido para los extranjeros entender la política de Estados Unidos en la actualidad. Igual pasa en México. Además, para la psicología latina -muy diferente a la anglosajona-, la constitución política es un ideal. Otro aspecto que dificulta que los "americanos" entiendan se debe a que no pueden separar "la cuestión mexicana" de sus intereses políticos y económicos.

Inman cita con frecuencia a Wilson para defenderlo. Recuer$\mathrm{da}$ al lector el cambio de actitud de muchos latinoamericanos hacia Estados Unidos gracias a sus 14 puntos, así como a su participación en la primera guerra mundial. Desde una lectura simple, Inman considera que esto produjo el incremento del comercio, así como el intercambio de profesores y estudiantes. Citando a un empresario estadounidense, afirmaba que la administración de Wilson estaba cautivando a la opinión pública latinoamericana y esto beneficiaba los negocios del país. Este cambio se frenaría de golpe si se producía una intervención. La reacción de América Latina es clara: a la ya declarada Doctrina Calvo y Drago se sumó la Carranza como un llamado a una solidaridad (latino) americana para hacer respetar la soberanía de estas naciones frente a las presiones del extranjero. Apelando al derecho internacional, al terminar el capítulo cita una leyenda inscrita en el edificio de la Unión Panamericana en Washington: "Dios nos ha hecho vecinos. Dejemos que la justicia nos haga amigos". 34

En el segundo y tercer capítulo, titulados “ ¿Es el presente disturbio en México una revolución real?” y “¿Qué tipo de hombre es Carranza?”, su postura antiintervencionista es más clara al adentrarse en una explicación de una revolución que aún no ha terminado y que tiene, a su juicio, numerosas y legítimas causas

${ }^{34}$ Inman, Intervention in Mexico, pp. 30-42. 
para haber estallado. Al igual que la de Rusia, anticipaban los levantamientos contra las clases propietarias. ${ }^{35}$ Madero es para él, un líder del liberalismo mexicano, un héroe nacional que fue asesinado brutalmente por los conspiradores (Huerta a la cabe$\mathrm{za}$, pero también menciona las simpatías con los reaccionarios del embajador de Estados Unidos). Era uno de esos jóvenes "progresistas" que no miraban con recelo a Estados Unidos, pero a quienes les era imposible seguir mirando el proceso que seguía el país sin participar. Dando algunos ejemplos sobre cuánto gana un jornalero en México, Inman esperaba convencer al lector de que el gobierno de Díaz era despótico y, por lo tanto, ilegítimo. Queda claro también que es una república sin democracia.

Poco habla de los otros revolucionarios: de Zapata menciona que fue asesinado, pero que conocía bien a su gente del sur; y al referirse a Villa no lo acusa, pero sí lo califica como bandido, mencionando que dada su cambiante alianza ha hecho que para el gobierno mexicano sea difícil atraparlo (como para ellos lo fue en su momento el joven James). El bandidaje, del que tanto acusa la prensa estadounidense a México para justificar una intervención armada, es para él un fenómeno social comprensible, al igual que lo fue en Estados Unidos después de la guerra civil. ${ }^{36}$

La figura sobre la cual se extendió fue la de Carranza, dedicándole el tercer capítulo. Recuerda cuando lo conoció en 1911 al encontrarse con Madero en la frontera internacional para derrocar a Díaz. Rememora cuando le mostró el Instituto del Pueblo que él dirigía en la ciudad de Piedras Negras. ${ }^{37} \mathrm{El}$

\footnotetext{
35 Inman, Intervention in Mexico, p. 52.

${ }^{36}$ Los intervencionistas representaban a México como un lugar infestado de bandidos y brutalidad, concentrándose en las atrocidades de rapto, pillaje y asesinato. O'BRIEN, “Oil, diplomacy and intervention”, pp. 73-74.

${ }^{37}$ El Instituto fue de gran utilidad a la revolución de Madero porque una vez empezada, las personas estaban necesitadas de conocer cómo debían realizarse las elecciones, cómo organizar un partido político, etc., pidiendo ayuda al
} 
“verdadero Carranza” no se sentía atraído por las armas ni por el poder, sólo mostraba interés por los cambios que podía hacer en su estado. Halagó a su familia, compuesta por su esposa y dos hijas, con quienes construyeron una relación cercana (su esposa y sus hijas eran calladas y no pretenciosas, pese a ser de una clase media alta). Recuerda cómo tuvo el honor de trasladarlos a Texas cuando Carranza tuvo que ponerse al mando de las tropas, y cómo presenció la despedida en el puente fronterizo, lo cual le generó un profundo respeto. Por todo esto, cree honestamente en los principios que guían su liderazgo, pues es un hombre "intensamente devoto". Es consciente, empero, de que el ejército constitucionalista cometió abusos, como ha sucedido en todos los períodos de la historia en que existen movimientos políticos violentos. ${ }^{38}$

En el siguiente capítulo (cuarto), Inman se adentra en el mundo de las percepciones que tienen los mexicanos de los americanos. Aclara que para el público latinoamericano es frecuente escuchar críticas a la intromisión de los Estados Unidos en los asuntos internos. Cita el poema de Rubén Darío “Oda a Roosevelt”, a Manuel Ugarte (Elporvenir de América Latina), a Francisco García Calderón (América Latina). Esas palabras se escribieron antes de la (primera) guerra mundial, por lo que es necesario aprovechar la situación actual (promovida por Wilson) para cambiar la opinión negativa que tienen de los estadounidenses. ${ }^{39}$

Instituto, el cual prestó su auditorio para realizar reuniones donde se discutieron muchos de los cambios que se darían poco después. Lo calificó como "un experimento" al mostrar cómo "los mexicanos aceptaban un programa de educación práctica relacionado con aspiraciones nacionalistas". Por este motivo, cuando un grupo tomó las calles de esa ciudad el 16 de septiembre para quemar las casas de los extranjeros, pasó por el Instituto sin hacer ninguna demostración.

38 InMAN, Intervention in Mexico, p. 116.

39 INMAN, Intervention in Mexico, pp. 120-122. 
En el capítulo sobre la situación en México el autor describe algunas de sus experiencias en un viaje que realizó a México entre febrero y marzo de 1919. La intención era mostrar al público estadounidense que la situación económica no era peor que antes de la revolución, y que incluso se abrían posibilidades para negocios (como el mercado de libros). Al comentar sobre Saltillo, menciona a Carranza y Madero. Habla de la cercanía entre ellos (por lo cual es incomprensible que haya personas que crean que él complotó contra el presidente). Otra anécdota sobre el encuentro con dos hombres que eran asiduos al Instituto del Pueblo en Piedras Negras le permite resaltar el tipo de educación moral que llevaban los misioneros, el cual era exitoso y útil para acercar el modelo estadounidense. ${ }^{40} \mathrm{Al}$ narrar su paso por San Luis Potosí, Aguascalientes y Zacatecas observó la permanencia de las colonias de americanos, los cuales, salvo casos excepcionales, habían sido tratados correctamente; también mostró que los americanos avecindados se encontraban mejor que durante el porfiriato. En la ciudad de México, la narración se concentró en una conferencia donde reunió con los misioneros de Estados Unidos que estaban en México (del 17 al 22 de febrero de 1919). Recordó cómo el presidente Carranza manifestó estar de acuerdo con el programa educativo que llevaban los misioneros y que no había ningún motivo para preocuparse, pues contaban con la simpatía del gobierno para organizar las escuelas agrícolas. Agradecía que los misioneros hubieran hecho lo posible por mantener la amistad entre ambos países, esparciendo una

${ }^{40}$ En Saltillo se encontró con dos hombres que habían sido asiduos al Instituto del Pueblo en Piedras Negras. Uno de ellos había comprado el teatro de Saltillo para proyectar películas americanas recientes. Cuando eran estudiantes ellos trabajaban en las tiendas de la estación de tren y después de "adquirir las ideas de progreso de las clases nocturnas y los clubs de debate" decidieron realizar ese emprendimiento para "enfatizar la democracia". Uno de ellos se dedicó a introducir filmes americanos mientras que el otro vendía cosas americanas por catálogo. Inman, Intervention in Mexico, pp. 170-172. 
buena imagen del país en Estados Unidos. Les pedía que, si así lo sentían, al regresar a su casa comentaran que el gobierno mexicano era amigable y que encontrarían una situación distinta a la que prevalecía dos años antes. ${ }^{41}$ Posteriormente, Inman se encontró en privado con el presidente en el Palacio Nacional, donde comprobó que ya no se encontraba rodeado de generales, con uniformes y armas, con lo que pretendía aminorar la idea de que el gobierno era bolchevique. Para dar muestras del cambio, recordó su participación en un evento organizado en la Escuela Nacional Preparatoria, donde el profesor y director Moisés Sáenz (educado en Washington) lo invitó junto con otros estadounidenses a participar de la asamblea para demostrarles que eran bienvenidos, idea afirmada por las conversaciones sostenidas con los estudiantes. Una percepción similar tuvo de la Escuela Normal de México, donde participó en otro acto y conversó con los maestros que externaron su preocupación por no tener libros de texto (oportunidad aprovechada por Inman para remarcar la viabilidad del negocio). ${ }^{42}$

El último capítulo, dedicado a exponer su idea sobre cómo deberían de ser las futuras relaciones entre México y Estados Unidos, inicia con una lista de afirmaciones: que los mexicanos no han tenido una justa posibilidad de ser educados en los últimos 400 años; que la revolución fue un verdadero cambio social y no hay vuelta a atrás; que los jóvenes de México, muchos de ellos educados bajo la influencia estadounidense, están trabajando en una nueva política educativa para su país y es esperable

${ }_{41}$ Tras la reunión que sostuvo Carranza con los 20 delegados de las misiones estadounidenses en la reunión de febrero de 1919, la Conferencia formuló una declaración que fue ampliamente difundida en Estados Unidos en la que se subrayaba que era evidente que el país estaba retornando lentamente a la estabilidad política, social y económica. Reconocían las dificultades que aún enfrentaba el gobierno para restaurar el país, por lo que los misioneros mostraban su simpatía y esperaban que la democracia se instalara para promover una amistad estrecha entre ambos países. BASTIAN, “Los propagandistas”, p. 344.

42 InMAN, Intervention in Mexico, pp. 162-203. 
que gradualmente cumplan sus metas; y que el pueblo mexicano debe desarrollar su "carácter" y para eso los amigos de México seremos llamados a ayudar. ${ }^{43}$

Para sumar argumentos pragmáticos, deja en claro las dificultades que implicaría para Estados Unidos una intervención: sería difícil enfrentarse a 15000 mexicanos unidos por un hombre; sería necesario educar a 5000 indios que nunca aprendieron el español; habría que acordar con una población de peones que están más atrasados que lo que estuvieron los esclavos negros. Por todo esto, afirma, el pueblo estadounidense no debe desear una intervención armada sino pedir a sus gobernantes que se dediquen a solucionar sus asuntos internos. Las relaciones diplomáticas entre ambos países deberían ser cordiales, ocupando Estados Unidos un nuevo papel, pues "no es ya la revolución la que debe ser detenida, sino la evolución la que debe ser guiada”. Esto implica que, amén de los cambios económicos, debe atenderse uno educativo para formar el carácter del mexicano. De nada sirve distribuir las tierras a personas que no tienen ambición de trabajarlas o que no tienen el entrenamiento necesario para proteger sus derechos y cumplir con sus deberes como

${ }^{43}$ Como señala Rubén Ruiz, formar el carácter implica para Inman que los misioneros de Estados Unidos tienen un lugar principal en el desarrollo de México, pues pueden ser un modelo de "actitudes frente a la vida" al tener un "espíritu de servicio". Para formar ese carácter en los mexicanos era necesario un programa educativo que fuera "práctico y nacionalista". Para ello, Inman planteó fundar una institución de educación superior que estaría en la ciudad de México, pero dirigida por los misioneros en esta ciudad y desde Nueva York. En ella se formarían los líderes que con actitudes prácticas serían buenos ciudadanos. RuIz, "Panamericanismo y protestantismo", pp. 270-271. Las tratativas iniciaron en mayo de 1919, cuando Inman consultó con el embajador mexicano en Washington, Bonillas, sobre la posibilidad de crear una universidad protestante en México. Contaba con el apoyo del departamento de Estado, las fundaciones privadas Carnegie y Rockefeller, así como del presidente de la Universidad de Cincinnati. Durante su visita a México, Inman recibió el apoyo de Carranza y otros líderes, sin embargo, la caída de éste en 1920 hizo imposible el proyecto. BaSTIAN, "Los propagandistas", p. 341. 
ciudadanos. Los "indios verdaderos" tienen un interés natural por la tierra, pero qué pasa con los millones de peones que han estado en contacto con la vida moderna (y sus vicios). Citando al presidente Teodoro Roosevelt al hablar de los brasileños (pero piensa que es aplicable a los mexicanos), dice: "el carácter debe superar el genio y el intelecto". Citando a otro expresidente, Butler, se pregunta si debe ser el cuidador de su hermano, lo cual es peligroso a su juicio porque implica una actitud de superioridad. Además, los soldados estadounidenses que fueron a pelear en la Gran Guerra están regresando a casa, por lo que considera que el país debía girar su atención a un problema mayor, "la moral de la guerra", oportunidad que se presenta ahora. Entonces, para cerrar, repite la pregunta y la deja abierta: ¿qué vamos a hacer sobre México ${ }^{44}$

\section{EL AMIGO DE MÉXICO (¿ENEMIGO DE ESTADOS UNIDOS?) PRIMERAS REPERCUSIONES DEL LIBRO}

A los pocos días de haber salido el libro, Inman publicó un artículo en el cual reforzaba su postura al afirmar el derecho de México de legislar sobre el subsuelo debido a que fue una tradición que pasó de la corona de España a la nación al hacerse independiente. Pese a esta afirmación, intentó calmar a la audiencia asegurando que Carranza no tenía intención de confiscar los actuales yacimientos, en manos de extranjeros, sino de exigirles que pagaran impuestos y garantizar que los nuevos fueran explotados por mexicanos. ${ }^{45}$

Otro acto de presión fue el que realizó el presidente de la Liga, McDonald, quien escribió al senador Fall (13 de agosto), presidente de la Comisión de Asuntos Internos del Senado,

${ }^{44}$ Inman, Intervention in Mexico, pp. 209, 214, 243.

45 Artículo publicado en Survey Graphic el 30 de agosto de 1919 y citado en Woods, "Samuel Guy Inman", pp. 55-56. 
encargado de investigar, reportar y sugerir sobre los asuntos mexicanos que afectaran la vida y propiedades de los ciudadanos americanos. ${ }^{46}$ En su carta, McDonald explicaba que el Comité Mexicano estaba preparado para proporcionarle "información fidedigna sobre la situación mexicana”, por lo que junto con la primera carta envían tres capítulos del libro de Inman, así como una copia del informe oficial sobre la industria del petróleo en México. Al día siguiente escribe de nuevo preguntando si puede informarle cuándo iniciarían las audiencias. Le aclara que varios miembros del comité habían estado en aquel país recientemente y querían informar sobre las condiciones actuales, por lo que estarían “gustosos de comparecer”. Mediante una pregunta retórica le solicita discreción con los testigos para que "como estadounidenses leales" no se preste a propaganda que ha explotado la prensa recientemente contra un país con el cual, le recuerda, Estados Unidos tiene aún "un trato amistoso". ${ }^{47}$

Como representante de la Liga, Inman asistió a la comparecencia el 8 de septiembre de 1919 a las 11 de la mañana en el edificio de las Oficinas del Senado en Washington. Inició leyendo una declaración escrita en donde afirmaba que, dado el contacto de los misioneros americanos y sus intereses en México, conocen más a su pueblo que cualquier otro americano.

${ }^{46}$ Lou, "Fall Committee", pp. i-iv, 52. Las audiencias del subcomité se realizaron en distintas ciudades de Estados Unidos y sumaron 257 testigos, los cuales, según el autor, pueden dividirse en tres grupos, los intervencionistas, los antiintervencionistas y los neutrales, que no estaban a favor ni en contra de una intervención armada. El reporte final del subcomité se reveló el 28 de mayo de 1920, recomendando una intervención para garantizar la protección de los americanos, pero esto no fue apoyado por el gobierno. Poco después serían acusados sus miembros de tener intereses personales en dicha recomendación. Durante la presidencia de Haring, Fall se desempeñó como secretario del Interior, pero en 1924 se reveló que recibió sobornos de los empresarios petroleros, por lo que fue declarado culpable y encarcelado. Las transcripciones se publicaron en dos volúmenes titulados Investigación en Asuntos Mexicanos. 47 Méndez Reyes, “Comparecencia del Dr. Samuel Guy”, pp. 134-135. 
Agregó que 50\% de los jóvenes líderes del gobierno mexicano ha sido influenciado por escuelas misioneras o ha sido educado en Estados Unidos y afirmó que Carranza no era el responsable del radicalismo de la Constitución de 1917, pero para mantener la unión de su partido lo había aceptado, intentando cambiar algunas cuestiones después. El senador Fall mantuvo una actitud hostil interrumpiendo para desacreditarlo por sus fuentes de información. El senador lo acusó por la afirmación que realizó en la carta de febrero de ese año (la carta que llamó a la rebelión), donde Inman afirmó que "El Congreso de Estados Unidos estaba determinado a una intervención”. Después de seis horas de interrogatorio Inman admitió que estaba involucrado en la propaganda antiintervencionista. Tuvo que reconocer también que su afirmación de que la propaganda intervencionista había sido financiada por sumas enormes de dinero eran rumores.

Inman refirió que como secretario del Comité de Cooperación en América Latina visitó las misiones protestantes en México, Perú, Chile, Argentina y Brasil en 1914. En este viaje constató los "enormes prejuicios que existían contra los Estados Unidos”. En cambio, durante su viaje de 1917 (a aquellos países, además de Bolivia, Paraguay y Uruguay) encontró que, a raíz de la entrada de este país en la primera guerra mundial, se sentían más cercanos al librar una batalla en nombre de todas las "democracias libres", cambio de opinión que se operó sobre todo entre los intelectuales de las universidades. Menciona también el panamericanismo y la solidaridad americana como aspectos básicos para que Estados Unidos pueda "tener influencia en todo el mundo", como la revolución en México. Aunque lo anterior conformó un proceso difícil, las nuevas clases dirigentes son jóvenes educados en escuelas misionales (50\% de los líderes municipales, gobernadores, secretarios y senadores); ellos están tomando "las mismas medidas que nosotros quisiéramos implementar si estuviéramos ahí; tal y como lo hicimos en Cuba, por ejemplo, al tomar el control de sus políticas nacionales". Por 
esto es que los misioneros (y editores de la prensa misionera) se oponen terminantemente a una intervención armada. Inman aclaró de distintas maneras que Carranza pensaba modificar la Constitución para evitar que el artículo 27 fuera retroactivo con la intención de concordar con los Estados Unidos. ${ }^{48}$

Durante el interrogatorio se mencionó el libro, el cual Fall no había podido leer completo porque acababa de ser publicado (sólo los capítulos enviados por McDonald). La comisión se detuvo en el hecho de por qué o para qué escribir ese libro. Inman respondió cautelosamente que ahí puso sus consideraciones sobre la "verdadera revolución” que experimentó México. Recordó una anécdota de cuando estaba dando clases en aquellos años en México y el gobierno de Díaz le informó que no debía enseñar la Constitución, y cómo ahora los jóvenes podían aprenderla libremente y eso era un gran paso hacia la democracia. Las preguntas, empero, se dirigieron a establecer el contacto con Carranza, a quien afirmó conocer personalmente desde antes de la Revolución y haber leído el Plan de Guadalupe. En ese punto, la comisión dejó el tema del libro para centrarse en la legitimidad de Carranza de ser presidente y en las afirmaciones del general Alvarado, a lo cual Inman respondió de manera breve y evasiva afirmando que no era un crítico para responder eso; ante ello el presidente de la comisión leyó en voz alta la carta redactada por Inman (31 de julio de 1919) en la cual se dirige a los Consejos Misionales que asistieron a la Conferencia de la ciudad de México en febrero para llamarlos a la protesta contra la intervención porque esto acabaría con el programa misionero en México. En la carta afirmaba que la Liga de Asociaciones

\footnotetext{
48 Es interesante que Inman afirma que la revolución de Madero comenzó el 20 de octubre de 1910, pero que el periodo revolucionario inició hasta 1912, cuando los “desórdenes se generalizaron en el país”, y al justificar esto, compara el proceso seguido por China en esos años desde el levantamiento encabezado por Chiahg Kai-Shek. Méndez Reyes, “Comparecencia del Dr. Samuel Guy”, pp. 137-149.
} 
de Naciones Libres se reunió en Washington con otros editores y periodistas, revelando que existía una campaña de propaganda financiada por los petroleros, quienes, aunque no habían sufrido expropiación alguna, querían hacerse cargo de toda la riqueza petrolera que aún faltaba por descubrir en México. Recuerda a los misioneros que, dado que los pastores ofrecieron sus servicios a la Revolución, nunca como ahora, la "cristiandad evangélica” había tenido tanto respeto en México entre el pueblo y que una intervención sería un caos, primero, porque los protestantes mexicanos lucharían contra los invasores para defender a su país; segundo, porque los misioneros estadounidenses también deberían aliarse; de otro modo, serían acusados de estar vendidos al “oro yankee". En la carta Inman pedía que cada uno escribiera para presionar a sus congresistas en Estados Unidos en contra de la intervención y que además publicaran en la prensa religiosa argumentos antiintervencionistas. La lectura de la carta fue un gran revés durante el interrogatorio, ya que después de esto el jurado lo atosigó de preguntas para descubrir quién la había leído y cómo algunos fragmentos llegaron a la prensa en México y en Estados Unidos. Las acusaciones siguieron hasta que la sesión terminó a las 6:10 de la tarde para reunirse nuevamente al otro día, no sin antes regañar a Inman, quien a juicio del jurado no debió haber escrito el libro si no tenía pruebas suficientes y directas, provocación a la que Inman no respondió. ${ }^{49}$

Al día siguiente, el martes 9 de septiembre, prosiguieron con el interrogatorio, ahondando en el objetivo como autor al escribir el libro. " ¿Quiere que la audiencia entienda que el libro que usted ha publicado sobre la intervención en México deba ser una guía para la gente de este país con referencias generales a los negocios mexicanos y auxiliarlos para determinar cómo deben actuar con México?”, a lo que Inman respondió que lo publicó

49 Méndez Reyes, “Segunda Parte de la Comparecencia del Dr. Samuel Guy”, pp. 125, 126, 136-142, 145, 204, 205, 207, 230-231. 
en ese momento para que la opinión pública la conociera. A pregunta expresa, Inman respondió que la editorial pagaba la publicación del libro, y a él le darían regalías si se vendía cierto número de ejemplares. El libro volvió a ser mencionado cuando Fall intentó demostrar que los juicios ahí vertidos no tenían fundamento. Para defenderse Inman leyó un párrafo de la página 175 en el que se menciona la corrupción en el ejército, hecho que era reconocido por Carranza, quien intentaría controlarlo. Pese a las muchas preguntas para hacer que Inman reconociera que era un propagandista de Carranza, el misionero se mantuvo firme en que la intención del libro era dar a conocer las condiciones de México. Asimismo, cuando el senador intentó asustarlo con que la nueva constitución impediría su libre trabajo como protestante en México, respondió que Carranza en conversación privada le había asegurado que no se modificaría nada en cuanto al trabajo de las misiones. A su vez, al acusarlo de que no tenía referencias directas para afirmar sobre el tema de las concesiones en México, señaló que esta información la obtuvo del libro México Bárbaro de John Kenneth Turner, al que considera una autoridad indiscutible. Una y otra vez, el jurado recaía en citas del libro a las que, tras su lectura, seguían eternas preguntas con la intención de demostrar que no tenía conocimiento de primera mano para realizar tales afirmaciones. Para finalizar, el presidente de la comisión preguntó cuánto tiempo le había llevado preparar el libro, cuánto escribirlo y si alguien le había ayudado -aportándole información o solicitándole que lo escribiera-, a lo que Inman respondió que había escrito el libro por capítulos, algunos en febrero de 1919 cuando estaba en México, y que lo entregó a la imprenta en junio, trabajando arduamente en su escritura por las noches, sin que nadie le sugiriera su escritura ni le ayudara con información. Inman termina la audiencia sosteniendo lo que dice el libro y que no estaba arrepentido de haberlo escrito. Sin embargo, cuando lo quisieron acusar de haberlo hecho como propaganda antiintervencionista 
en un momento adecuado, el misionero respondió que cuando empezó a escribirlo no existía el mismo interés en las cuestiones mexicanas, a lo que Fall agregó irónicamente que el libro había aportado "al interés por los asuntos mexicanos". ${ }^{0}$

El segundo día de la audiencia, el New York Times publicó una entrevista a Inman, donde se le presentaba como el secretario ejecutivo del Comité de Cooperación para América Latina y un "seguidor de Carranza”. En ella aclaró que era miembro de la Liga de Naciones Libres y que ésta se encargaba de hacer propaganda a favor del reconocimiento del gobierno mexicano. Agregó que había sido amenazado con un juicio por difamación (aunque se negó a responder de quién venía dicha amenaza); respecto al financiamiento de la propaganda antiintervencionista, Inman respondió que el viejo comité (¿de cooperación?) dejó un pequeño fondo (cuatrocientos dólares) que fue organizado justo antes de la expedición punitiva de Pershing en México (1916), fondo que fue entregado a la Liga para realizar el trabajo. ${ }^{51}$ Además, Inman respondió que eran todos los fondos de que disponía el trabajo de propaganda. Al cuestionarle nuevamente sobre la Liga, preguntaron si De Bekker era empleado de ella, si ésta utilizó sus artículos para la propaganda y si eso habría influenciado a la prensa americana; a todo ello contestó afirmativamente. ${ }^{52}$

Durante los siguientes meses, la Comisión siguió interrogando testigos (257, por lo que la compilación de testimonios fue de 3400 páginas). Tras la comparecencia de Inman, atestiguaron otros miembros de la Liga que habían publicado libros

50 Méndez Reyes, “Comparecencia de Samuel Guy Inman”, pp. 185, 186, 197. 51 Inman y otro misionero mencionaron que la Liga pudo mantener al Comité de Cooperación porque el pago de sus misioneros dependía del consejo de misiones y ellos sólo daban algo para las expensas. BALDwin, Protestants and the Mexican Revolution, p. 145.

52 "Inman questioned on Mexico charges", New York Times (9 sep. 1919), p. 1: 2 . 
antiintervencionistas, como Leander J. De Bekker y Arthur Thompson, quienes al igual que Inman fueron desestimados por no tener pruebas de que la intervención estaba patrocinada por los productores de petróleo. Para contrarrestar las acusaciones se llamó a otros testigos, representantes de las empresas petroleras, quienes de manera cautelosa consideraron la intervención militar como el último recurso, inclinándose más hacia una serie de medidas de presión progresivas para desacreditas al presidente mexicano y precipitar una rebelión interna. ${ }^{53}$

México no actuó directamente para defender a Inman, pero se mantuvo atento al proceso por las implicaciones que esto le trajera. ${ }^{54}$ Días después de la comparecencia ante el Subcomité Fall, Ramón O. Negri, cónsul de México en Nueva York, escribió de manera confidencial a la Secretaría de Relaciones Exteriores para solicitar que se considerara su proposición anterior (enviada el 21 de agosto) de que México hiciera una protesta formal contra Estados Unidos por las investigaciones que estaba realizando la Comisión del Senado sobre la situación de México. ${ }^{55}$ Poco

53 Entre las medidas se mencionó el embargo de todos los préstamos, el cierre de los canales de comercio, demostraciones navales y la cooperación con los mexicanos anticarrancistas. Gilderhus, "Senator Albert B. Fall and 'The Plot Against México'”, pp. 302-303.

54 Informa que el Comité de Investigación del Senado se trasladará a Nueva York en tres semanas (aproximadamente el 15 de septiembre) para continuar con la investigación sobre México, y que además de llamar al cónsul a declarar visitarían el consulado para averiguar si era cierto que el gobierno de México había gastado una suma de dinero en la propaganda de prensa y la agitación de los medios obreros. Solicita se le informe si debe prestar declaración y qué hacer en caso de la posible visita. AHSRE, exp. L/131/1861, 19 de julio de 1918. Telegrama de Hilario Medina para el presidente Carranza citado en ENRÍQUEZ Perea, Hilario Medina, pp. 75-76.

55 De Negri a SRE. 1 de octubre de 1919. Fol. 1-116. Negri era "un ferviente partidario de la Revolución bolchevique” y en octubre de ese año fue visitado por dos funcionarios del gobierno soviético en Nueva York, quienes lo visitaron para plantear la posibilidad de establecer una misión comercial rusa en México, medida que no tuvo el consentimiento del presidente Carranza, por 
después comentó que dicha comisión se reuniría nuevamente en dos semanas y que los amigos de México en Estados Unidos le comentaron que sería agradable que el gobierno realizara una "vigorosa protesta" porque las investigaciones realizadas eran hostiles para un país con el que mantenía relaciones diplomáticas (recordó que hacía pocos meses Japón había hecho algo similar y la investigación había sido suspendida). Para darle documentación precisa, le comenta que está recolectando folletos publicados por el comité de investigaciones de negocios mexicanos para enviárselos, así tendría conocimiento de "los insultos lanzados a nuestros hombres públicos, y al país en general”. Recuerda que si fallara la conciliación política aún les quedaría la vía diplomática. Además, consideraba necesario actuar debido a que, si no, perderían la buena voluntad de un sector de estadounidenses que los apoyaba. Además, su discreción hará que siga ganando adeptos entre los "elementos inteligentes del pueblo hispanoamericano de aquí", con lo que tal vez en algún momento la simpatía pueda convertirse en ayuda concreta. ${ }^{56}$

Un mes después De Negri escribió de nuevo a las autoridades mexicanas de manera confidencial para enviarles un boletín de la Asociación Protectora de los Intereses Extranjeros en México en el que venían las declaraciones de William B. Mitchell, quien había sido gerente del Banco de Londres y México durante la Revolución. Advierte que dicha Asociación actúa de "mala fe" y publicita sus resultados para calumniar a México. Por esto, sugiere a sus superiores que el gobierno mexicano abra una investigación semejante a la emprendida por la Comisión Fall

lo que Negri insistió en la importancia que esto tendría para el país, aduciendo además que otras potencias como Inglaterra e Italia estaban inclinándose a reconocer al gobierno ruso y que el estadounidense estaba arrepentido y dispuesto a enviar agentes especiales a Rusia. SPENSER, El triángulo imposible, p. 81.

${ }^{56}$ AHSRE, 13-10-66 (I). Ramón P. de Negri a SRE. 1 de octubre de 1919, fol. 1-2. 
para acusar a esta Asociación de perjuicios y, tras demostrar su culpabilidad, embargar las propiedades de sus miembros. ${ }^{57}$

La síntesis de la declaración de Mitchell era a todas luces crítica del proceso revolucionario de México, en especial contra Venustiano Carranza. Inicialmente lo acusa de haber tomado una suma de dinero del gobierno de Coahuila tras la caída de Madero para pagar a las tropas. Esta información la obtuvo de Ernesto Madero, tío del presidente y ministro de Finanzas, quien (cito) afirmó que era necesario poner a Carranza en su lugar si no regresaba ese dinero. Tras el levantamiento del general Huerta, Carranza arrestó al agente del Banco de Londres y México en Saltillo. Tras continuar con otros acusados aliados de Carranza (Obregón, Pablo González, Murguía y Diéguez), prosiguió con la situación financiera e industrial de México, citando a Inman para contradecir lo dicho en su libro "para elogiar el régimen de Carranza en México”. Acusa a Inman de declaraciones falsas, como la que sostiene que Huerta echó a los estadounidenses de aquel país. Se opone también a afirmaciones de Inman, como que los mexicanos son "hostiles" con los estadounidenses porque los han "explotado", cuando en su opinión los trabajadores prefieren trabajar con extranjeros porque reciben mejor trato y paga, sin contar con que el propio Carranza había reconocido la necesidad de estos capitales extranjeros. Para terminar, Mitchell propone la intervención financiera como una solución al problema mexicano, pero con un gobierno mexicano que lo garantice. ${ }^{58}$

Dos meses más tarde, el cónsul arremetió nuevamente al enviar al subsecretario de Relaciones Exteriores información

57 AHSRE, 13-10-66 (I). Ramón P. de Negri a SRE. 21 de noviembre de 1919, fol. 1.

58 AHSRE, 13-10-66 (I). National Association for the Protection of American Rights in Mexico, fol. 1-4. El texto fue traducido al español y enviado con urgencia y de forma confidencial al secretario de Gobernación de México para que estuviera al tanto. AHSRE, 13-10-66 (I). Ramón P. de Negri a Manuel Aguirre Berlanga, s. f. 
confidencial proveniente de "una persona de entero crédito", quien le expresó que conversó con el director general de Correos de Estados Unidos, el señor Burleson, quien le confirmó que la intervención en México era inminente. En la recientemente celebrada Junta de Gabinete, Wilson (gravemente enfermo por una inflamación en la médula) y dejó en manos del secretario de Estado y del de Guerra la cuestión de México. Al día siguiente se efectuó una reunión entre el secretario de Estado, Lansing: el secretario de Guerra, Baker, y los embajadores de Inglaterra y Japón para tratar "la cuestión mexicana". El informante le aclaró que era un golpe político interno de los demócratas para ganar las próximas elecciones porque la intervención los eximiría de que "no se les exijan cuentas por los gastos y responsabilidades incurridas durante la guerra europea". Es tarde para cualquier arreglo, afirma, porque el general Pershing salió ya para la frontera, por lo que para la próxima semana "estarían casi todas las fuerzas americanas reconcentradas en la frontera con México". ${ }^{59}$

Al finalizar los dos días que duraron las declaraciones, la reputación de Inman quedó lastimada al ser presentado como un propagandista de Carranza y un ignorante de los asuntos mexicanos, asustándolo incluso con que podía ser acusado por traición a su patria. A raíz de esto y de que el Comité de Cooperación de América Latina recibía donaciones de magnates petroleros se pensó en quitarle el cargo de secretario, pero la mayoría de los miembros se opuso defendiendo su derecho a hablar de sus convicciones y a defender una verdad en la que también creían. Pocos años después, Inman fue reivindicado cuando se

59 AHSRE, 13-10-66 (I). Ramón P. de Negri a Hilario Medina, 29 de noviembre de 1919, fol. 1-2. En diciembre el embajador de México en Estados Unidos, Ignacio Bonilla, intentó desacreditar al subcomité bajo el argumento de que respondían a los intereses petroleros de la Asociación Nacional de protección de derechos americanos en México, por el cual expresaba un profundo odio porque estaba seguro de que conspiraban contra el régimen de Carranza. EDWARDs, “United States-Mexican relations, 1913-1916”, p. 118. 
descubrió la colusión ilegal entre Fall y el petrolero Doheny. Sin embargo, en lo inmediato las dificultades continuaron: su libro desapareció misteriosamente de las tiendas poco después de su aparición en el Subcomité para atestiguar y cuando preguntó al presidente de la Association Press al respecto, éste le respondió que se había incrementado la oposición a su libro desde que dio testimonio. No se pudo esclarecer el paradero de los libros perdidos, aunque los rumores eran que Doheny había dado esa orden. Por ello, la editorial comenzó a tomar recaudos ante una posible segunda edición: le pidió a Inman que cancelara una cita que tenía el editor Harris con James McDonald, de la Liga de Asociaciones de Naciones Libres, y que pusiera una advertencia de que ciertos pasajes del libro no podían ser verificados. Inman se rehusó a responder preguntas sobre su testimonio y advirtió a la editorial que los "hombres de petróleo" estaban tratando de intimidarlos y que la supresión de partes del libro traería una tormenta de indignación. La relación entre el autor y la editorial se deterioró. Inman denunció que no escribieron a la lista de posibles lectores que les dio, donde la mayoría eran religiosos y organizaciones internacionales. El libro, declaro el autor, "fue asesinado" por las actitudes de la editorial, la cual tras una disculpa decidió cancelar el contrato. A fines de 1920 se reeditó por la compañía George Doran, pero su efectividad disminuyó (vendiéndose no más de 2000 ejemplares) porque en el transcurso de esos meses se había producido un cambio favorable en México. ${ }^{60}$

Pese a la categórica declaración de Inman sobre el libro, éste llegó a varios puntos del continente, posiblemente debido a que en algunos casos fue enviado por el propio autor. ${ }^{61}$ En septiem-

60 Woods, "Samuel Guy Inman and Intervention in Mexico", pp. 365-366.

${ }^{61}$ Por ejemplo, el 4 de septiembre de 1919, Inman escribió en hoja membretada del Comité de Cooperación en América Latina una carta al intelectual argentino José Ingenieros para enviarle su libro porque consideraba que representaba la opinión de la mayoría de las personas en Estados Unidos 
bre aparece una reseña en Lima en la famosa revista Mercurio Permano, escrita por el joven estudiante Edwin Elmore. Para el reseñista es evidente que el desorden actual de México es parte de un proceso lógico de acomodamiento tras los cambios realizados. También lo es que haya interesados en que Estados Unidos intervenga (los republicanos que se oponen a los principios liberales de Wilson), a quienes identifica como la "aristocracia internacional de los más fuertes”. Ahí inicia la referencia al libro de Samuel Guy Inman, el cual refleja esas corrientes de opinión que se enfrentan a los deseos de controlar y conquistar México, ya sea de manera política, militar o comercial. Reconoce en el autor un "hombre conocedor de México" y también entendido en que es en ese momento cuando se libra en Estados Unidos una batalla en el Congreso para decidir sobre la posición del gobierno al respecto. Traduce unas palabras publicadas en el periódico neoyorkino The Evening Post (publicado el 16 de agosto) del autor del prefacio, el profesor Shepherd, donde se pregunta si México es un Estado soberano e independiente o una región colonial explotada por el extranjero. Elmore asume las palabras de Shepherd de que en caso de intervenir se convertiría en un "conflicto de razas". Recuerda también que Estados Unidos proclamó en el siglo xIx durante la invasión francesa el derecho de México para "quedar árbitro de sus destinos”. Por último, y para dar mayor peso a la historia de Estados Unidos, recuerda que Lincoln combatió la política de conquista de Polk; cuando dio su discurso en 1948 protestó por la manera en que se produjo la guerra contra México. ${ }^{62}$

que se encontran preocupadas por las intervenciones. Esperaba recibir sus comentarios y si pensaba que era interesante para el público argentino; estaría gustoso de que realizara una reseña para la Revista de Filosofía que él dirigía. Por último, le pide que le comente cualquier sugerencia para favorecer la circulación del libro en Argentina. CEDINCI, A.6.1, SAA/8-4/4.3. 4 de septiembre de 1919, Samuel Guy Inman a José Ingenieros.

62 Mercurio Peruano, n. 15, año II, vol. III (sep. 1919), pp. 230-237. 
Ese mismo mes apareció en The Christian Century un anuncio publicitario del libro de Inman, a quien presentan como "una reconocida autoridad de las cuestiones panamericanas que ofrece al público pensante americano un punto de vista con información valiosa sobre los hombres, el movimiento y las posibilidades que tiene México", proponiendo "una política ilustrada y constructiva para las futuras relaciones entre los dos vecinos". ${ }^{63}$ Es interesante señalar que en lugar de reseñar el libro le dan amplio espacio para reproducir partes de él. Al número siguiente, en ese mismo diario se publicó un extenso artículo con un título provocador: "What kind of man is Carranza?", el cual es una síntesis del capítulo correspondiente del libro. Es interesante que hayan escogido esa parte del libro debido a que el artículo se publica pocos días después de la declaración de Inman en la Comisión Fall, y a diferencia de la declaración escueta donde negó ser amigo de Carranza, en el artículo se reforzó lo puesto en el libro: que entre ambos existió una fuerte amistad que inició desde la revolución en $1911 .{ }^{64}$ En ese mismo medio de prensa, se retoma el libro de Inman como la voz de alarma de los cristianos contra la intervención armada al señalar el verdadero ánimo de los petroleros. Por ello espera que el gobierno de su país encuentre otra manera de solucionar el problema mexicano que no sea la vía armada ${ }^{65}$ Es evidente que para el grupo era muy significativa la obra de Inman. El interés de esta publicación por la obra de Inman era tal que para el siguiente año comentó que la

${ }^{63}$ El libro se podía comprar escribiendo a la oficina del diario en Chicago y pagando \$ 1.50 más 16 centavos del envío. InMan, "Intervention in Mexico", The Christian Century, septiembre 4 de 1919, p. 20 (se repite el anuncio en la p. 21). ${ }^{64}$ Samuel Guy Inman, "What kind of man is Carranza?", The Christian Century (25 sep. 1919), pp. 10-13. En ese mismo número sale de nueva cuenta una publicidad del libro (y de otros) de la editorial Association Press (véanse pp. 21 y 23). Anuncios similares se publicaron en el siguiente número (23 oct. 1919), pp. 22, 27.

${ }^{65}$ Editorial, The Christian Century (4 dic. 1919), pp. 6-7, y nuevamente anuncio del libro en p. 22. 
Iglesia estaba organizando clases urgentes para estudiar el libro de Inman, al tiempo que anunciaba otras conferencias de Inman sobre Centroamérica. ${ }^{66}$

En el ámbito académico el libro tuvo menor impacto. En el transcurso de 1920 se publican algunas reseñas en Estados Unidos. Una de ellas, escrita por un autor que se identificó con las siglas D.H.K., define de manera muy sintética que el libro es una "exhibición popular de las condiciones sociales y las fuerzas progresivas en México”, una petición contra la intervención a favor de la comprensión, la paciencia y la asistencia educativa. Asume que el autor entiende que tras la gran revolución "México necesita que le den la oportunidad de trabajar en su propia salvación", aludiendo a la comprensión del lector al asemejarlo con el proceso que siguió Estados Unidos tras su guerra civil. Recuerda que Inman asume que puede ser explotado legítimamente sin necesidad de intervenir, y que de hacerlo los países sudamericanos se alinearían con México. ${ }^{67}$

Otra reseña publicada casi de manera simultánea en la conocida revista The Hispanic American Historical Review, por Herbert Ingram Priestley, asume de inicio que, en este tema, Inman es la persona más competente para hablar porque gran parte de la evidencia e información de México la ha recogido él de primera mano al vivir en aquel país durante varios años como misionero. En este sentido, su historia, sin propaganda, tiene el propósito de "servir a un trabajo altruista en el cual está comprometido". La introducción del profesor Shepherd está acorde al tono del libro

${ }^{66}$ Inman, como secretario ejecutivo del Comité de Cooperación de América Latina, representó a los misioneros en la conferencia realizada en Guatemala (marzo 26-29). Editorial, The Christian Century (8 abr. 1920), pp. 17, 18. Nuevamente se repitió el anuncio del libro en ese número (p. 20) y también en marzo, véase (4 mar. 1920) p. 21. Para el mes de junio, se informó que Inman ya había visitado Haití y Santo Domingo, donde encontró "un territorio virgen para el esfuerzo misionero", The Christian Century (10 jun. 1920), p. 23.

67 D.H.K. “Review”, en American Journal of Sociology, 25: 4 (ene. 1920), p. 503. 
al apelar a la tolerancia, la sinceridad y el frío juicio. Tras ir presentando los capítulos, el reseñista se pregunta si los disturbios en México son una verdadera revolución, porque de ser así es necesario esperar a que, tras los efectos destructivos, inicien los cambios. Si se observan esos cambios se verá cómo los hombres (norteños en su mayoría) formados por la Iglesia (protestante) están en el gobierno, iniciando el "progreso". Finaliza afirmando que es un buen libro que se lee sin problemas ni provocaciones y que es deber de los “americanos" el asistir sin interferencia el proceso de trasmisión de poder en México para ayudarlos a estabilizar el gobierno. Esto traería “paz y prosperidad” a México y "mantendrá la conciencia limpia de los Estados Unidos”. ${ }^{68}$

Por su parte, la reseña escrita por Chas. H. Cunningham durante su estadía en la ciudad de México parte de considerar el libro como el esfuerzo realizado por un misionero que tiene la autoridad suficiente para discutir problemas significativos de la política y la economía con el fin de fomentar simpatía y tolerancia por México en el público americano. Es parte de la propaganda protestante misionera que se opone a las corporaciones americanas del petróleo que presionan para realizar una intervención. Adopta una postura similar a la de Inman al referirse al desconocimiento que tenemos sobre México. Sin embargo, en algunas ocasiones Cunningham plantea que Inman no tiene el conocimiento para probar lo que dice, aunque él también considere que se trata de la verdad, pues sus juicios parten de "un punto de vista religioso". Por ello, no es extraño que el tono del libro oscile entre la descripción de la realidad de México y un tono idealista por el cual se busca justificar y extender el trabajo de los misioneros en México. ${ }^{69}$

68 Herbert Ingram Priestley, Revies. Intervention in México by Samuel Guy Inman and William Shepherd, en Hispanic American Historical Review, 3: 1 (feb. 1920), pp. 53-56.

69 Chas. H. Cunningham, reseña en The Soutbwestern Political Science Quartely, 1: 2 (sep. 1920), pp. 192-194. 


\section{CONCLUSIÓN}

Inman fue un actor importante para entender esta pequeña trama de la historia. Falta información para definir si fue, como lo acusaron en la Comisión Fall, un "agente del carrancismo". Él se presentó como un “amigo (y conocedor) de México”, un misionero interesado en el futuro de éstas en América Latina, o un americano que defendía la solidaridad continental como el verdadero panamericanismo. Lo que importa aquí es señalar que se movió en un espectro amplio en busca de aliados no solo geográficamente (sus viajes por México y el resto de América Latina) sino también políticamente. Su participación en el Comité de Cooperación de América Latina y, sobre todo, en la Liga de la Asociación de Naciones Libres da muestras de su habilidad como mediador en agrupaciones de misioneros protestantes y otros grupos de presión liberales. Aunque eran organizaciones distintas, ambas convergieron en 1919 en la campaña de prensa antiintervencionista.

El libro de Inman fue una pieza clave en las propuestas para resolver la "cuestión mexicana", pero debe ser entendido como parte de una serie de eventos, textos y comunicados que venían desarrollándose con anterioridad. La radicalización de algunos misioneros protestantes después de la revolución se conjugó con el proceso de reorganización de las misiones latinoamericanas en Estados Unidos y con la estrategia de Wilson para incorporar a su país a la Sociedad de las Naciones. Reconstruir la historia de este proceso escapa a los fines de este trabajo, pero llevó a contextualizar la aparición del libro en un entramado complejo de debates y luchas de poder. Por ello, las repercusiones de la obra muestran hasta qué punto tuvo un efecto político más que literario o académico.

Buscó convencer a una opinión pública estadounidense por medio de un discurso pragmático. Más que cuestionar la legitimidad de una intervención se cuestiona su eficacia y sobre todo 
los costos que esto tendría (en dinero, hombres y consecuencias negativas). Los adjetivos desfavorables utilizados en el libro para describirla como una lucha sangrienta y fratricida, se relacionaban siempre con la moraleja de que generarían disturbios y pérdidas para ambos países. Juega con el impacto de la primera guerra mundial, no sólo para recordar las pérdidas que acababan de sufrir sino para afirmar que en caso de intervenir destruirían la simpatía que había labrado Wilson para colocarse como un líder de la democracia. Además, sería un pésimo negocio tanto por motivos económicos como morales, porque frenarían el cambio iniciado tanto por los revolucionarios mexicanos como por los misioneros estadounidenses que ayudaron a que este cambio fuera posible.

De manera implícita, rechaza, por ende, la interpretación de la Doctrina Monroe como el destino manifiesto de Estados Unidos de expandirse sobre los débiles vecinos, quejándose de que aún hay americanos que siguen profesando la fe en este derecho y que son imperialistas de corazón. No cuestiona la doctrina, pero asume que debe mantener su sentido original (que Europa se quede fuera de los asuntos americanos), sentido que es aceptado por todos los países latinoamericanos y que permitiría romper la mala asociación entre panamericanismo y Doctrina Monroe.

Tampoco niega la función del capitalismo al aclarar que el capital de los estadounidenses es fundamental para los mexicanos. El problema radica en que los intereses de algunos capitalistas determinen la política exterior del país y que las concesiones que éstos tienen en México mantengan a sus trabajadores bajo un sistema de explotación. De hecho, su alegato contra la intervención no deja de tener un sesgo capitalista, pues repite de muchas maneras la idea de que, si México está estable, los bolsillos de numerosos estadounidenses no sólo no se verán afectados, sino que podrán expandir sus negocios. Para ello es necesario que se permita al país vecino gobernarse. 
Por eso su interés de limpiar la imagen de Carranza, afirmando en varias ocasiones que no sólo no sería un freno, sino un impulsor de las misiones protestantes. A eso se debe la atención prestada a recalcar que muchos de los hombres del gabinete de Carranza fueron educados por los protestantes en México o en Estados Unidos. Estos agentes de cambio buscarían que el progreso de México fuera guiado por la educación moral que defendían los misioneros. Como liberal estadounidense su postura mantiene no sólo la lógica civilizatoria del progreso sino también la religiosa, del avance moral. No es extraño que haya justificado la revolución mexicana como una evolución violenta, pero necesaria para romper con el yugo de Díaz, pero también de la Iglesia católica. Tampoco lo es que para Inman Estados Unidos sea un modelo a seguir para las otras naciones al considerar a este país como la democracia más desarrollada en el continente. Defiende su avance capitalista, pero critica los excesos de los inversionistas estadounidenses en México (petroleros en especial). México no debía salir de la órbita de control de Estados Unidos, pero era necesario un cambio de política exterior. En él, la diplomacia y las misiones jugarían un papel fundamental.

Esto nos lleva a reflexionar sobre un punto que si bien se tocó tangencialmente en este trabajo puede servir para futuras investigaciones. Me refiero a la pregunta lanzada hace algún tiempo por Evelia Trejo sobre si la expansión del protestantismo en estos países fue parte de la diplomacia estadounidense para extender su control sobre la región. Como ella señaló, durante el siglo xix los gobiernos mexicanos consintieron esta intromisión porque fue útil para fines económicos y políticos, en la batalla de los fines liberales por frenar el poder de la Iglesia católica en las cuestiones de Estado. Esta batalla fue aprovechada por el gobierno estadounidense para expandir el protestantismo. Por lo tanto ambos ganaron. ${ }^{70} \mathrm{Si}$ pensamos en el periodo es-

70 Trejo, “La introducción del protestantismo en México”, pp. 171-177. 
tudiado, sobre todo en el año de 1919, la respuesta no es tan simple porque existió mayor disenso entre los grupos de presión estadounidense. Inman aduce en su libro, así como en su defensa ante la Comisión Fall, que la intervención sería una incorrecta decisión política porque, amén de todo lo señalado, las misiones sufrirían las peores repercusiones. Esta suerte de advertencia estaba dirigida tanto a los misioneros (en busca de que apoyaran la causa antiintervencionista) como al gobierno de Estados Unidos, a quien parecía recordarle hasta qué grado la política y la religión no podían disociarse si se quería mantener la influencia en la región.

\section{SIGLAS Y REFERENCIAS}

AHSRE Archivo Histórico de la Secretaría de Relaciones Exteriores, Ciudad de México, México.

CEDINCI Centro de Documentación e Investigación de la Cultura de Izquierda, Buenos Aires, Argentina.

CEHM Centro de Estudios de Historia de México Fundación Carlos Slim, Ciudad de México, México.

Baldwin, Deborah J., Protestants and the Mexican Revolution. Missionaries, Ministers, and Social Change, Urbana y Chicago, University of Illinois Press, 1990.

Bastian, Jean-Pierre, "Los propagandistas del constitucionalismo en México (1910-1920)", en Revista Mexicana de Sociología, 45: 2 (abr.-jun. 1983), pp. 321-351.

Cardoza Orlandi, Carlos F., "From Christian Continent to Mission Field. The Missional Discourse of the Committee on Cooperation in Latin America and Protestant Latinamericans Concerning the Missional Needs of Latin America (1910-1938)", Dissertation submitted to the Faculty of Princeton theological seminary for the degree of doctoral of philosophy, Princeton, New Jersey, 1999.

Castleman, W. M. J., On This Foundation. A Historical Literary Biography of the Early Life of Samuel Guy Inman: Herald of Christian Cooperation, Advocate of Inter-American Friendship, Worker for the World Peace, and 
Pioneer in Social Action Covering the Period 1877-1904, Missouri, The Bethany Press, 1966.

EDWARd, Warrick, Ridgely, "United States-Mexican Relations, 1913-1916: Revolution, Oil and Intervention", tesis de doctorado, Luisiana, Lousiana State University, 1971.

Enríquez Perea, Alberto (introducción y compilación), Hilario Medina. Constituyente de 1917, México, Universidad Nacional Autónoma de México, 2016.

Fediakova, Evguenia, "Protestantismo misionero norteamericano en América Latina en el siglo xx", en Persona y Sociedad, xxi: 1 (2007), pp. 9-37.

Gilderhus, Mark T., "Senator Albert B. Fall and 'The Plot Against Mexico'”, en New Mexico Historical Review, xLvIII: 4 (oct. 1973), pp. 299-312.

Inman, Samuel Guy, Intervention in Mexico, Nueva York, Associated Press, 1919.

Inman, Samuel Guy, The Panama Congress and the Disciples of Christ, Indianápolis, Indiana, The Christian Woman’s Board of Missions, 1916.

Inman, Samuel Guy, The Crucial Hour in Latin America, Indianápolis, Indiana, The Christian Woman's Board of Missions, 1908.

Inman, Samuel Guy, The Mexican Question, Indianápolis, Indiana, The Christian Woman's Board of Missions, 1911.

InMAN, Samuel Guy, "No comprendo": a message from Mexico, Indianápolis, Indiana, The Christian Woman's Board of Missions, 1913.

Lou, Dennis Wingsou, "Fall Committee: An Investigation of Mexican Affairs”, tesis de doctorado, Indiana, Indiana University, 1963.

Matute, Álvaro, “El fantasma de la intervención. Los Estados Unidos y México en 1919", en Estudios de Historia Moderna y Contemporánea de México, 16 (1993), doc. 208, pp. 79-100.

McDonald Steward, Barbara, Advocate for the Doomed. The Diaries and Papers of James G. McDonald, 1932-1935, editado por Richard Breitman, Barbara McDonald Stewart y Severin Hochberg, Indiana University Press, United States Holocaust Memorial Museum, 2007. 
Méndez Reyes, Jesús, “Comparecencia del Dr. Samuel Guy Inman -misionero evangélico, escritor y erudito-como presunto simpatizante de México frente a los daños causados a ciudadanos estadounidenses durante la Revolución Mexicana. Comisión Fall”, en Meyibó, Revista de Investigaciones Históricas, 4: 7 (ene.-jun. 2013), pp. 131-189.

Méndez Reyes, Jesús, "Segunda parte de la comparecencia del Dr. Samuel Guy Inman -misionero evangélico, escritor y erudito- como presunto simpatizante de México frente a daños causados a ciudadanos estadounidenses durante la Revolución mexicana”, en Meyibó, Revista de Investigaciones Históricas, 5: 10 (jul.-dic. 2015), pp. 123-196.

Méndez Reyes, Jesús, “Comparecencia de Samuel Guy Inman, presunto simpatizante de la Revolución mexicana frente a daños a estadounidenses", en Revista de Historia de América, 154 (ene.-jun. 2018), pp. 175-250.

Meyer, Lorenzo, Los grupos de presión extranjeros en el México revolucionario, 1910-1940, México, El Colegio de México, 2012.

Mondragón, Carlos, Like Leaven in the Dough. Protestant Social Thought in Latin America, 1920-1950, Madison y Teaneck, Fairleigh Dickinson University Press, 2011.

O’Brien, Dennis J., "Oil, diplomacy and intervention: A study of United States petroleum interests in Mexico, 1917-1920", tesis de doctorado, Omaha, Nebraska, Univeristy of Nebraska, 1963.

Pita, Alexandra, "Panamericanismo y nación. La perspectiva de Samuel G. Inman”, en Anuario IEHS, 32 (1) (2017), pp. 135-154.

Ruiz Guerra, Rubén, "Panamericanismo y protestantismo: una relación ambigua", en Roberto Blancarte (comp.), Cultura e identidad nacional, México, Consejo Nacional para la Cultura y las Artes, Fondo de Cultura Económica, 1994.

Spenser, Daniela, El triángulo imposible: México, Rusia Soviética y Estados Unidos en los años veinte, México Centro de Investigaciones y Estudios Superiores en Antropología Social, Miguel Ángel Porrúa, 1997.

Trejo, Evelia, "La introducción del protestantismo en México. Aspectos diplomáticos”, en Estudios de Historia Moderna y Contemporánea, 11 (1988), pp.149-181. 
VÁzquez, Josefina Zoraida y Lorenzo Meyer, México frente a Estados Unidos-Un ensayo histórico, 1776-2000, México, Fondo de Cultura Económica, 2013.

WiLliams, Virginia, Radical Journalists, Generalist Intellectuals, and U.S.Latin American Relations, Nueva York, The Edwin Mellen Press, 2001.

Woods, Kenneth F., "Samuel Guy Inman: His Role in the Evolution of InterAmerican Cooperation”, tesis de doctorado en filosofía, Washington D.C., American University, 1962.

Woods, Kenneth F., "Samuel Guy Inman and Intervention in Mexico", en Southern California Quarterly, 46: 4 (dic. 1964), pp. 351-370. 
